\title{
Study of the Niobium Oxide Structure and Microscopic Effect of Plasma Processing on the Nb Surface
}

B. Giaccone ${ }^{1,2}$, M. Martinello ${ }^{1}$, J.F. Zasadzinski ${ }^{2}{ }^{1}$ FNAL, Batavia, IL 60510, USA - ${ }^{2}$ IIT, Chicago, IL 60616, USA

\section{Abstract}

A study of the niobium oxide structure is presented here, focusing on the niobium suboxides. Multiple steps of argon sputtering and XPS measurements were carried out until the metal surface was exposed. Subsequently, the sample was exposed to air for different time intervals and the oxide regrowth was studied. In addition, three $\mathrm{Nb}$ samples prepared with different surface treatments were studied before and after being subjected to plasma processing. The scope is investigating the microscopic effect that the reactive oxygen contained in the glow discharge may have on the niobium surface. This study suggests that the $\mathrm{Nb}_{2} \mathrm{O}_{5}$ thickness may increase. Nevertheless, since the $\mathrm{Nb}_{2} \mathrm{O}_{5}$ is dielectric, its thickening would not negatively affect the cavity performance.

\section{Plasma processing to mitigate FE}

Reducing FE through $C_{x} H_{y}$ removal from cavity Nb surface

Increasing the niobium work function by $10 \%$ results in $15 \%$ increase

in $\mathrm{E}_{\mathrm{acc}} \mathrm{O}_{2}+\mathrm{C}_{x} \mathrm{H}_{y} \rightarrow \mathrm{CO}+\mathrm{CO}_{2}+\mathrm{H}_{2} \mathrm{O}$
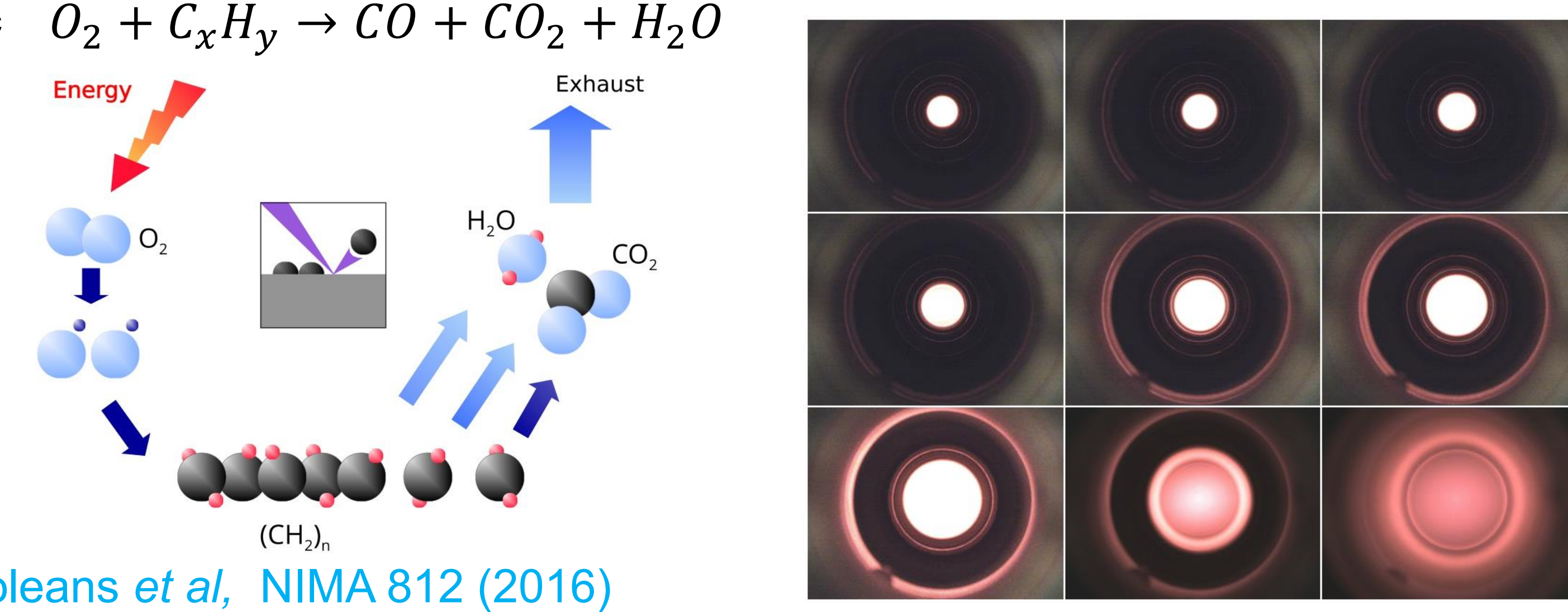

M. Doleans et al, NIMA 812 (2016)

P. Berrutti, B. Giaccone et al., J. Appl. Phys. 126, 023302 (2019)

\section{Oxide growth through air exposure}

Air exposure steps:

- $15 \mathrm{~min}$

- Additional $15 \mathrm{~min}$

- Additional $45 \mathrm{~min}$

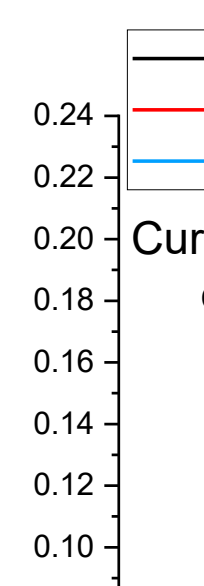 \\ -}
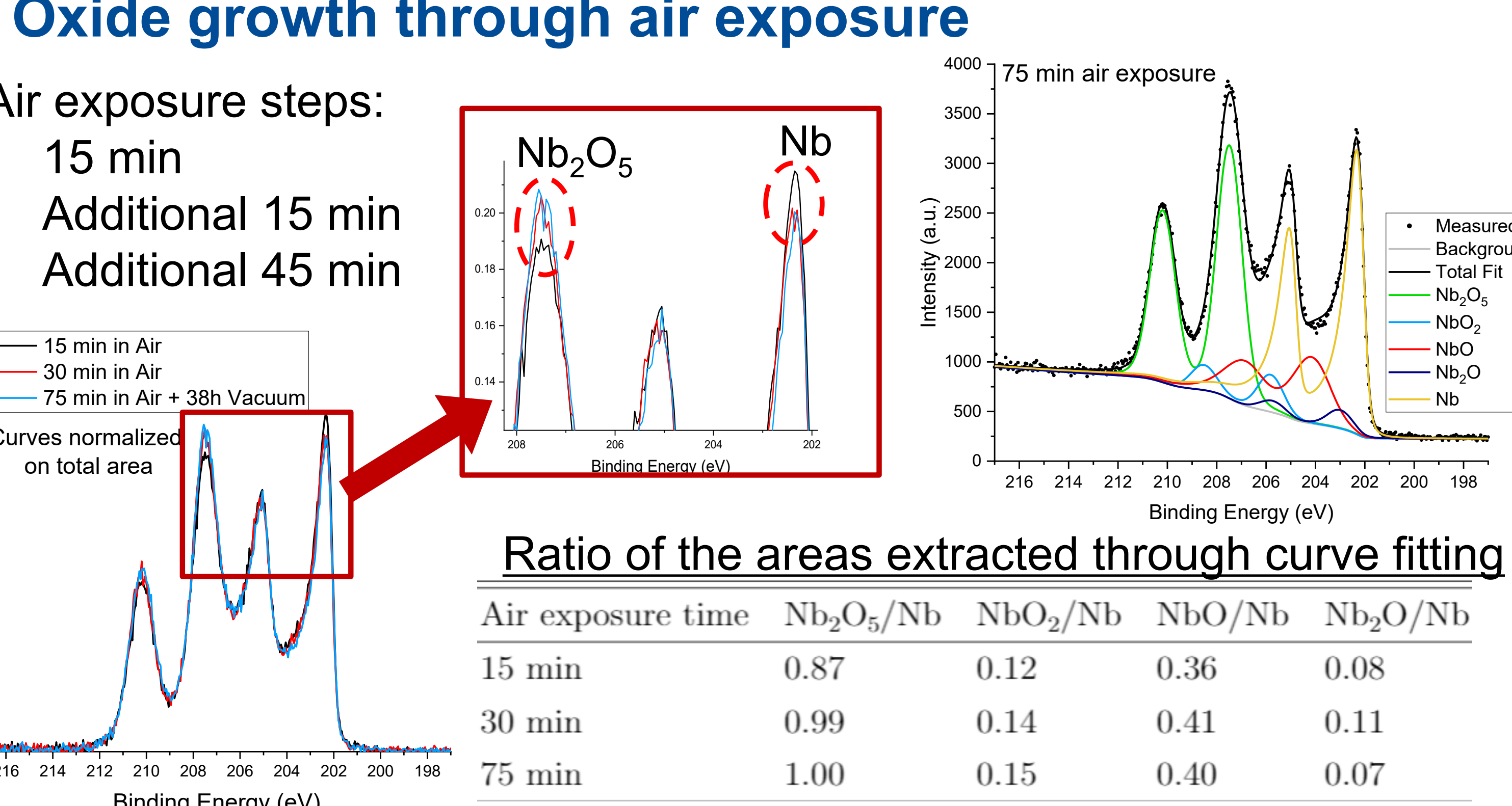

Ratio of the areas extracted through curve fitting \begin{tabular}{lllll}
\hline Air exposure time & $\mathrm{Nb}_{2} \mathrm{O}_{5} / \mathrm{Nb}$ & $\mathrm{NbO}_{2} / \mathrm{Nb}$ & $\mathrm{NbO} / \mathrm{Nb}^{2}$ & $\mathrm{Nb}_{2} \mathrm{O} / \mathrm{Nb}$ \\
\hline 15 & 0.87 & 0.30 &
\end{tabular} 30 min 0.99

$\begin{array}{lll}0.14 & 0.08 \\ 0.15 & 0.40 & 0.11\end{array}$

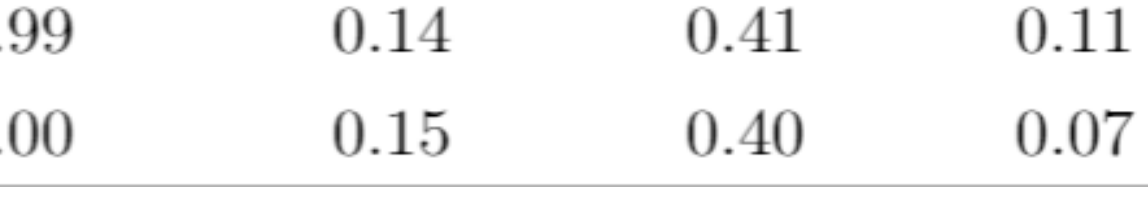

After 75 minutes of exposure to air: surface has not reached full oxidization.

Multiple suboxides were identified through curve fitting: $\mathrm{NbO}, \mathrm{NbO}_{2}, \mathrm{Nb}_{2} \mathrm{C}$ The initial measurements on the oxidized sample showed possible traces of $\mathrm{NbO}$ and $\mathrm{NbO}_{2}$, but no $\mathrm{Nb}_{2} \mathrm{O}$ was detected

\section{Argon ions sputtering on oxidized $\mathrm{Nb}$ sample}

- Sample preparation: 800 ${ }^{\circ} \mathrm{C} \times 3 \mathrm{~h}+20 \mu \mathrm{m} \mathrm{EP}+5$ min $\mathrm{HF}$ rinse

- After surface treatment: 1 week to fully oxidize prior to XPS measurement
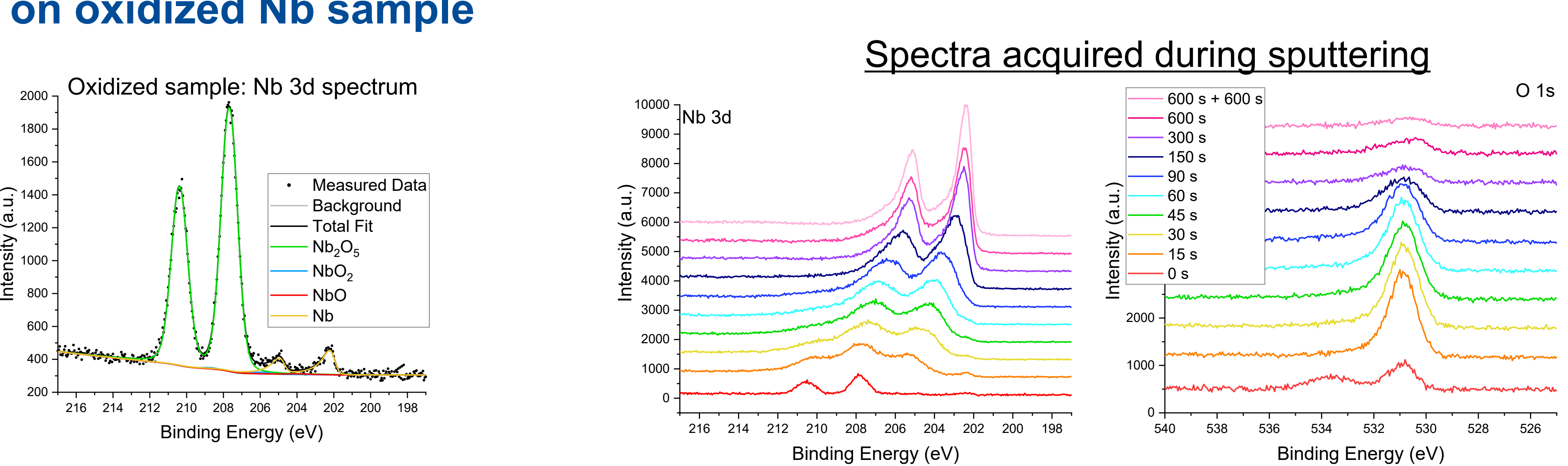

$\mathrm{Nb} 3 \mathrm{~d}$ : shift towards lower energy values as the oxidation state decreases

O 1s: initially three peaks are detected: niobium oxide, $\mathrm{C}-\mathrm{O}$ $\mathrm{C}=\mathrm{O}$. The niobium oxide peak is due to $\mathrm{Nb}_{2} \mathrm{O}_{5}$ plus the suboxides

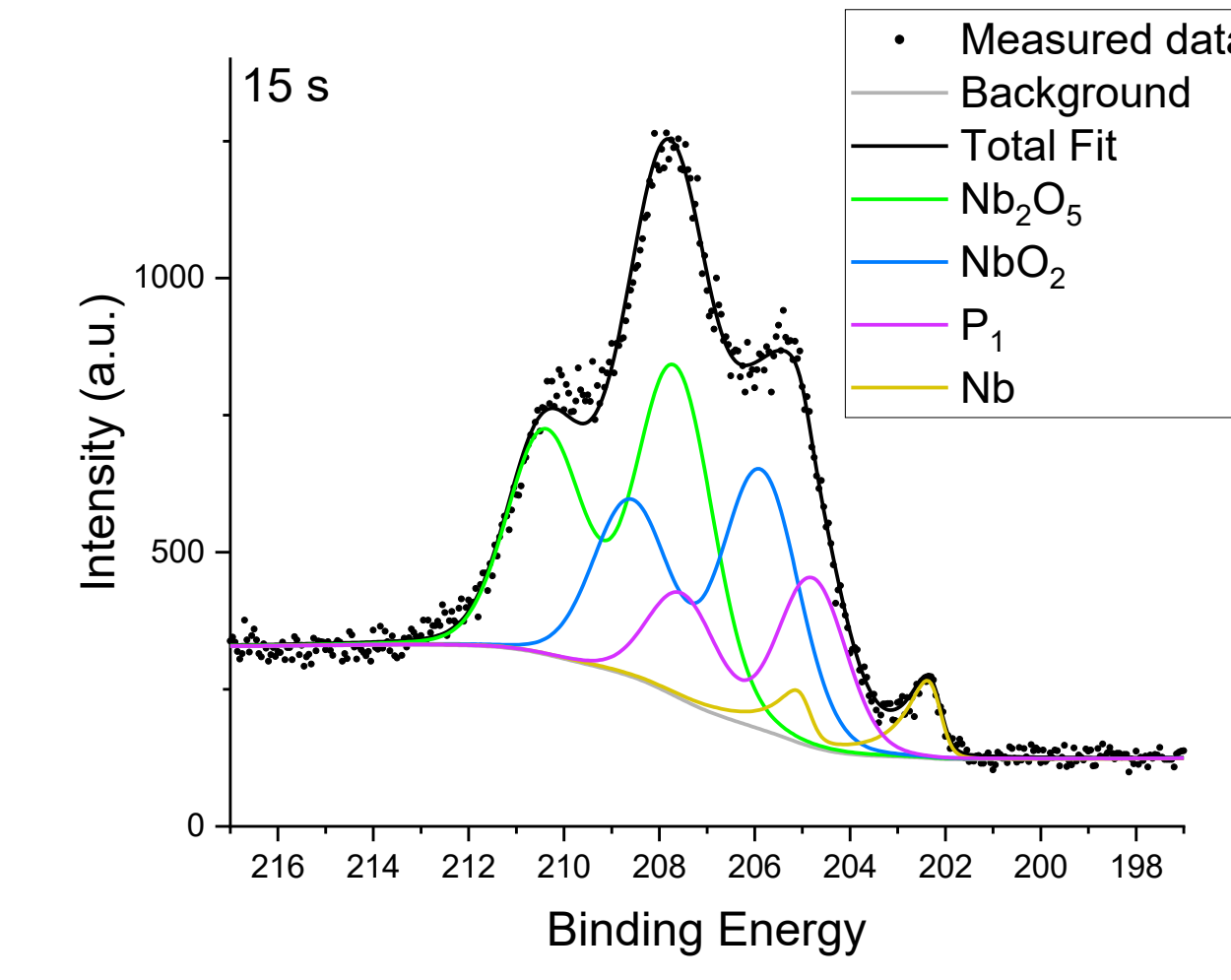

- Nb peak: $202.2 \mathrm{eV}$ - $\mathrm{P}_{1}: \mathrm{NbO}_{1+x}$ peak: $204.8 \mathrm{eV}$ - $\mathrm{NbO}_{2}$ peak: $205.9 \mathrm{eV}$ - $\mathrm{Nb}_{2} \mathrm{O}_{5}$ peak: $207.7 \mathrm{eV}$

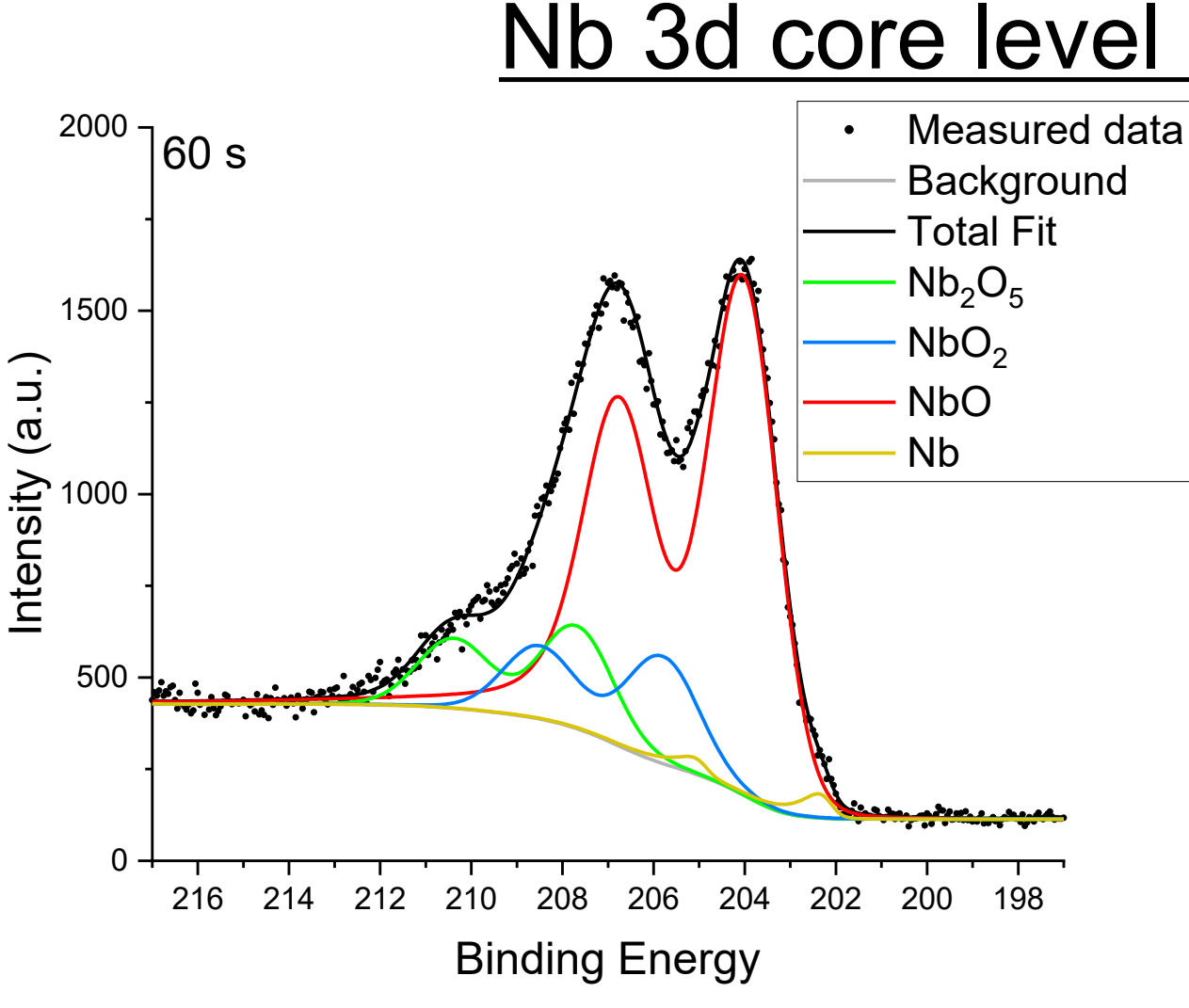

- Nb peak: $202.2 \mathrm{eV}$ - NbO peak: $203.8 \mathrm{eV}$ - $\mathrm{NbO}_{2}$ peak: $205.8 \mathrm{eV}$ - $\mathrm{Nb}_{2} \mathrm{O}_{5}$ peak: $207.8 \mathrm{eV}$

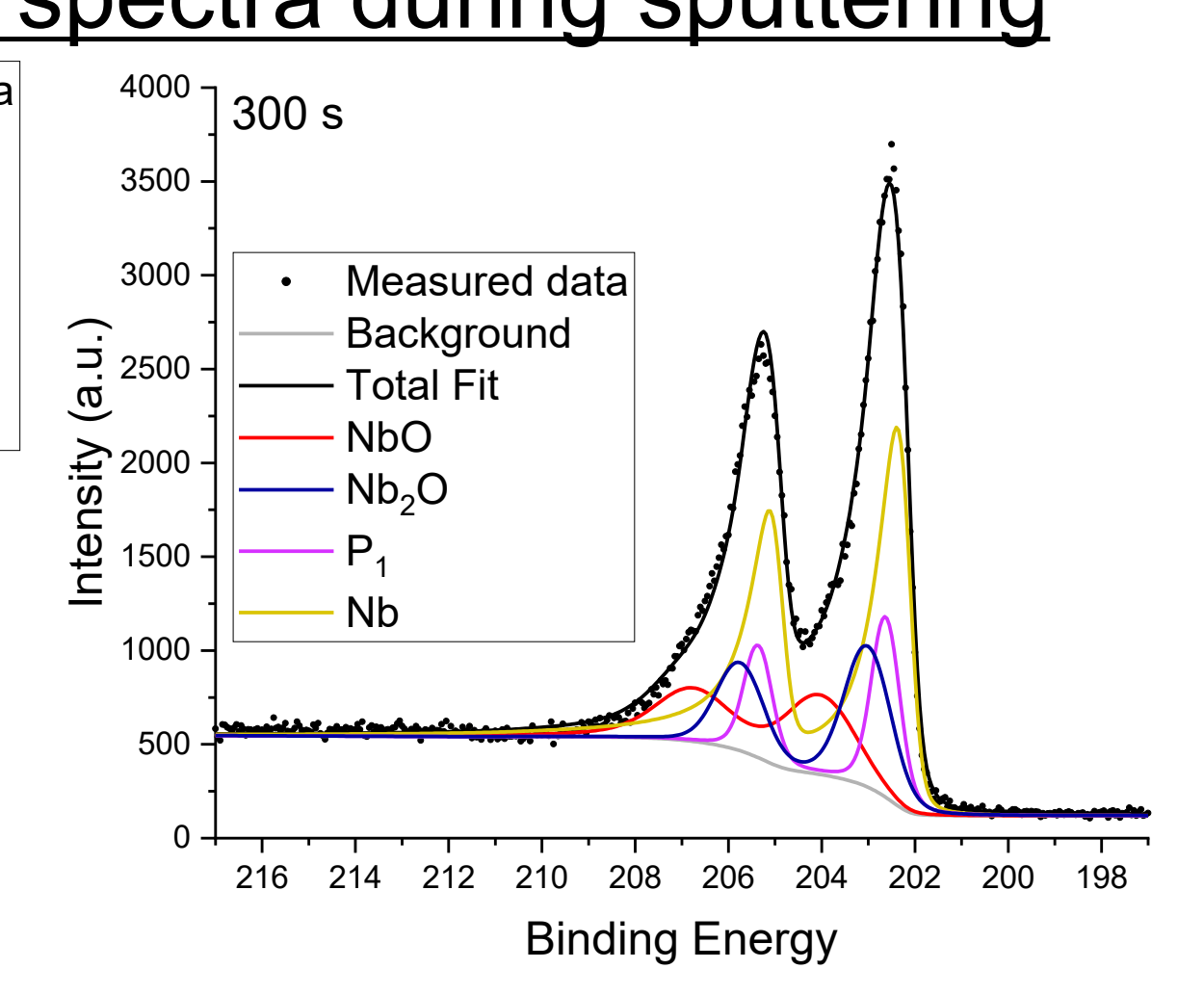
- Nb peak: $202.2 \mathrm{eV}$ - Nb $\mathrm{N}_{2+x}$ peak: $203 \mathrm{eV}$ - NbO peak: $203.8 \mathrm{eV}$

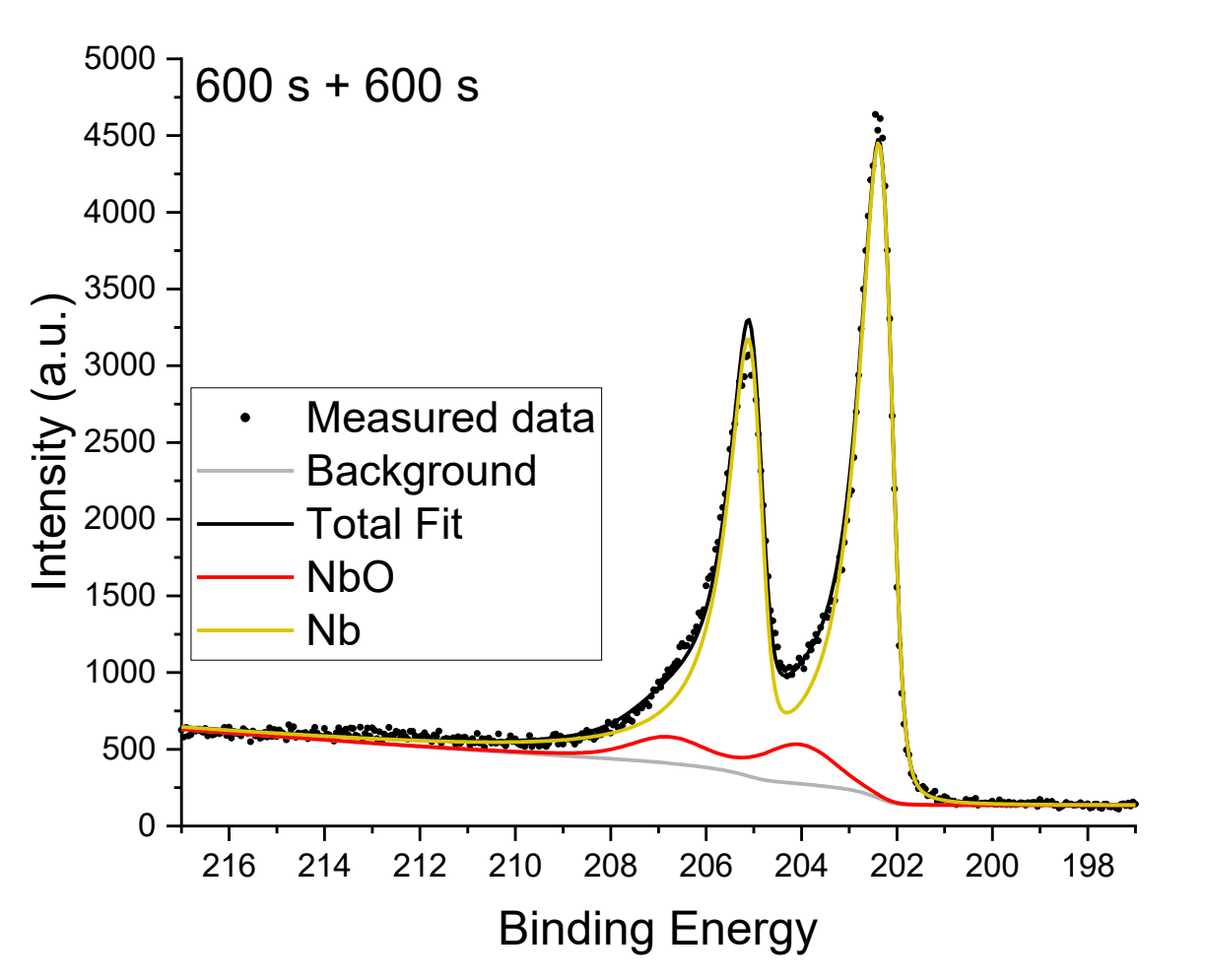

- Nb peak: $202.2 \mathrm{eV}$ - NbO peak: $203.8 \mathrm{eV}$

$P_{1}$ here identifies a nonstoichiometric oxide peak whose energy decreases at each sputtering step as its chemical state is modified by the Ar ions.

After $600 \mathrm{~s}$ of sputtering: sample kept under vacuum for $12 \mathrm{~h}$, followed by additional $600 \mathrm{~s}$ of sputtering and final measurement prior to oxide regrowth in air.

5. XPS analysis on plasma processed $\mathrm{Nb}$ samples

Sample preparation:

- PH 45: $800{ }^{\circ} \mathrm{C} \times 3 \mathrm{~h}+20 \mu \mathrm{m} \mathrm{EP}$

$\mathrm{PH}$ 35: 2/6 N doping + $5 \mu \mathrm{m} \mathrm{EP}+5 \mathrm{~min}$ $\mathrm{HF}$ rinse

PH 40: 2/0 N doping + $7 \mu \mathrm{m}$ cold EP

Samples were positioned on cavity iris and plasma processed for $6 \mathrm{~h}$

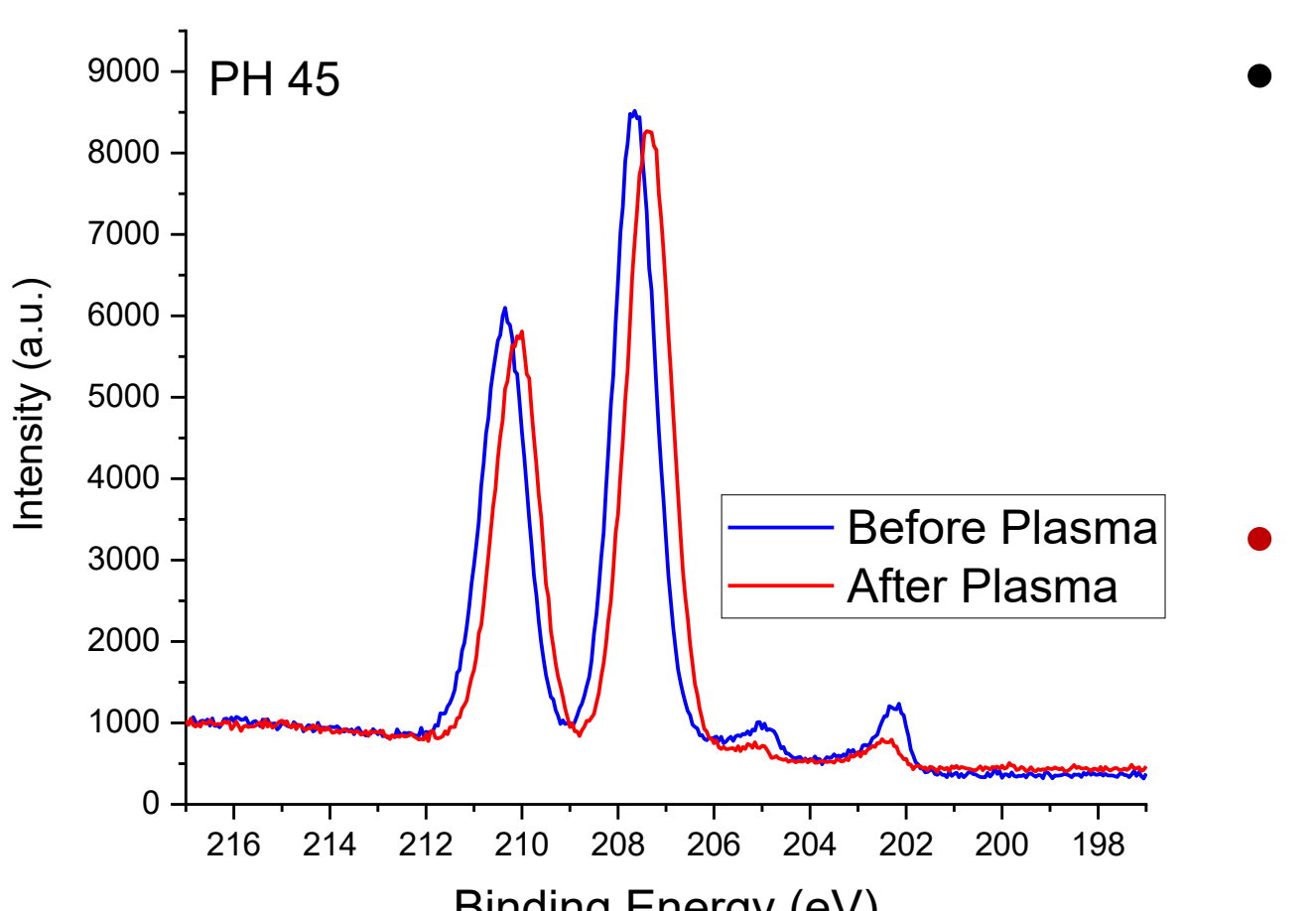

Relative intensity of $\mathrm{Nb}$ and $\mathrm{Nb}_{2} \mathrm{O}_{5}$ is modified: ratio of $\mathrm{Nb}_{2} \mathrm{O}_{5}$ area over $\mathrm{Nb}$ area consistently increases after plasma processing

$\Delta \mathrm{E}$ between $\mathrm{Nb}$ and $\mathrm{Nb}_{2} \mathrm{O}_{5}$ may be decreased after plasma processing. Further analyses are needed to understand if it is caused by plasma cleaning Similar results obtained on all three samples, independently of the surface treatment
No particular change was observed in the suboxide spectra

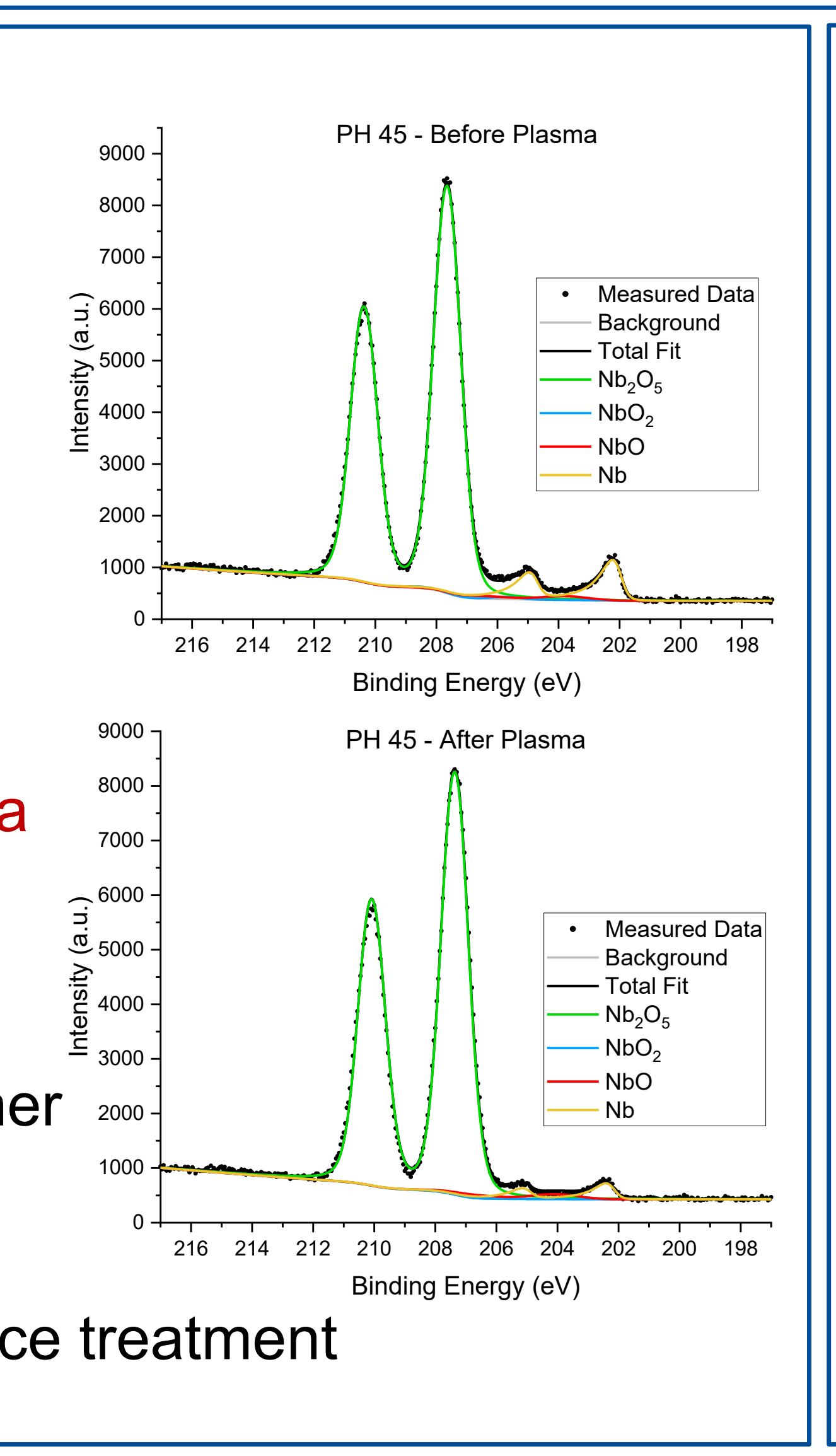

6. Conclusions

Sputtering and oxide regrowth: studied niobium oxide structure, identified multiple suboxides $\left(\mathrm{NbO}, \mathrm{NbO}_{2}, \mathrm{Nb}_{2} \mathrm{O}\right)$ and extracted parameters for data analysis

- Plasma processed samples:

- Consistent change in $\mathrm{Nb}_{2} \mathrm{O}_{5} / \mathrm{Nb}$ area ratio suggesting oxide thickening

- Possible reduction in $\Delta \mathrm{E}$ between $\mathrm{Nb}_{2} \mathrm{O}_{5}$ and $\mathrm{Nb}$ peaks. If caused by plasma processing, it may be due to the introduction of oxygen vacancies in $\mathrm{Nb}_{2} \mathrm{O}_{5}$ lattice.

- However, $\mathrm{Nb}_{2} \mathrm{O}_{5}$ is dielectric: thickness increase would not affect cavity performance 